\title{
O PAPEL DA CIÊNCIA NA SOCIEDADE.
}

\author{
OSCAR SALA
}

do Instituto de Física da Universidade de São Paulo.

Uma das principais características da civilização moderna é o extraordinário desenvolvimento da pesquisa científica, seja ela básica ou aplicada. Ciência e Tecnologia constituem as fontes principais de criatividade e dinamização da sociedade moderna, afetando de maneira substancial o padrão e a qualidade da vida em todo o globo e de maneira mais proeminente nos paises avançados onde a revolução científica encontrou terreno fertil.

Nesses paises, a ciência cresceu mais rapidamente do que qualquer outra atividade humana, e esse crescimento pode ser enfatizado em termos dramáticos: tram vivos!

- De cada oito cientistas que já viveram, sete ainda se encon-

- Os Estados Unidos investiram em Pesquisa e Desenvolvimento, em 1968, cerca de US\$ 25 bilhões. Em 1960 esse investimento foi menor do que um quarto de bilhão de dólares!

Entretanto, é importante que se tenha presente que somente numa sociedade onde exista um clima cultural, em que o impulso à curiosidade e o amor à descoberta sejam compreendidos e cultivados, pode a ciência florescer. Somente quando a ciência se torna profundamente enraizada como um elemento cultural da sociedade é que pode ser mantida e desenvolvida uma tecnologia progressista e inovadora, tornando-se, então, possivel uma associação íntima e vital entre ciência e tecnologia. Essa associação é uma característica da nossa época e certamente essencial para a manutenção de uma civilização com os níveis presentes de população e qualidade de vida. Estará a nossa sociedade propiciando um clima adequado para que a verdadeira ciência possa desenvolver-se? 
Apesar de reconhecermos a enorme importância e impacto das descobertas científicas e de suas aplicações através da tecnologia como meio de desenvolvimento e de promoçã̃o do bem-estar do homem, é tambem necessário que se reconheça que este sucesso é hoje encarado com apreensão e que importantes dúvidas são levantadas com relação ao papel da ciência na sociedade.

A sociedade moderna vive momentos de intensos conflitos, tornando-se óbvia a necessidade de maior atenção à sua infra-estrutura, alem da produção de bens e serviços para o consumo privado. Acumulam-se as deficiências na educação, saude pública, moradia, transportes urbanos, lazer público e na preservação do ambiente natural, frequentemente devassado e destruido por esta sociedade. Observa-se que, mesmo com o aumento da renda per capita (critério, hoje, reconhecidamente insatisfatório), cada incremento na produção material tem trazido como consequência grandes tensões na estrutura social em si. Obviamente, não é o crescimento econômico em si que gera essas tensões, mas sim o crescimento econômico definido exclusivamente em termos da produção de bens materiais para o consumo privado.

Devido a esses fatos, em alguns meios, a ciência é severamente atacada e criticada, criando-se um clima de reação emocional contra a ciência e a tecnologia; em outros, ela é considerada como a panacéia para a cura de todos os males. Obviamente, estas são posições extremas, mas que merecem ser analisadas para que se possa tomar uma posição consciente do relacionamento entre a ciência e a sociedade. Essa análise é particularmente importante para nós, onde o governo do país busca uma tomada de posição com relação à pesquisa científica e o desenvolvimento.

É possivel distinguirem-se, após a última guerra, três fases no relacionamento da ciência com o clima político nas nações desenvolvidas, particularmente nos Estados Unidos:

- A primeira fase - do fim da guerra até o início de 1960, caracterizada por uma enorme confiança do público com relação à pesquisa científica para a solução dos problemas que, nesse período, giravam, principalmente, em torno de questões de segurança nacional.

Os cientistas adquiriram alto prestígio no cenário político e as ciências físicas dominaram. Os físicos influiram de maneira decisiva na política de alocação de recursos para o desenvolvimento da ciência e tecnologia. As Universidades cresceram rapidamente. Foram criados os grandes laboratórios nacionais e multinacionais, como, por exemplo, o Laboratório Nacional de Brookhaven e, posteriormente, o 
CERN na Europa. Grandes somas foram investidas nesses laboratórios, particularmente na construção dos grandes aceleradores atômicos. Nasceu dessa maneira a chamada big science.

- A segunda fase, que prevaleceu na década de 60 , foi caracterizada pela gradual influência dos economistas e dos analistas de sistema na definição da chamada "política científica". Foi ampliado o escopo das pesquisas científicas objetivando-se o desenvolvimento sócio-econômico das nações. Nesta fase foram ventilados os problemas do gap tecnológico e os meios de transferência de tecnologia aos paises subdesenvolvidos. Esta fase de domínio do economista é a que atravessamos presentemente no Brasil. Ainda nesta fase, a atitude geral com relação à pesquisa ainda era de otimismo.

- A terceira fase, a mais recente, foi a de críticas severas e de desencanto com relação à ciência e tecnologia . A pesquisa científi$\mathrm{ca}$, na mente de muitos, foi associada aos graves problemas das guerras e com os de deterioração ambiental e social resultantes da ampla e rápida aplicação da tecnologia. Esta fase tem sido amplamente discutida por vários autores como, por exemplo, Reich em seu livro: The Greening of America.

Como decorrência desses fatos, segundo Weisskopf, estabeleceram-se três posições bem distintas da sociedade com relação à pesquisa científica:

- Atitude 1: Tem-se dado demasiada atenção às chamadas ciências básicas; grandes somas e enormes recursos humanos foram investidos em pesquisas exóticas de pouca ou nenhuma aplicação. Deve-se reduzir drasticamente o apôio econômico a esse tipo de pesquisa e incentivar, primariamente, as pesquisas que ofereçam rentabilidade imediata em termos de aplicações para a indústria, bem-estar público ou defesa nacional.

- Atitude 2: Quase toda pesquisa científica é nociva à sociedade, uma vez que ela é a fonte para as inovações industriais, as quais, em sua maioria, conduzem ou conduzirão a uma deterioração ambiental e social, ao desenvolvimento de armas que nos levarão às guerras de aniquilação ou a uma sociedade mecânica e computarizada.

- Atitude 3: Os métodos de trabalho utilizados nas ciências naturais - o chamado método científico - tem provado ser de grande sucesso na solução de problemas científicos e deve ser tambem empregado nas demais áreas de atividades humanas. 
Obviamente, as três atitudes apontadas são mutuamente exclusivas. Cada uma delas, em separado, indica uma visão muito parcial do papel da ciência na sociedade.

Vamos analisa-las, iniciando pela atitude número 1, que nega a importância das ciências básicas e que propõe que os gastos com estas sejam severamente reduzidos. Analisemos alguns fatos: H. B. G. Casimir, físico teórico e ex-diretor dos laboratórios de pesquisa da Philips, comentou e exemplificou de uma forma feliz e objetiva a importância da pesquisa básica nos processos de inovação. Diz ele:

"Tenho ouvido afirmações de que a importância da pesquisa acađêmica nas inovações é desprezivel. Esta é talvez a afirmação mais descabida que tive a oportunidade de ouvir" e continua: "Pode-se especular se os transistores poderiam ter sido descobertos por pessoas que não tivessem sido treinadas e não tivessem contribuido substancialmente para o desenvolvimento da mecânica ondulatória ou da teoria dos elétrons nos sólidos. $\mathrm{O}$ fato é que os inventores dos transistores eram pessoas versadas nesses assuntos e fizeram contribuições fundamentais à teoria quântica dos sólidos.

Pode-se perguntar se os circuitos básicos utilizados nos computadores teriam sido descobertos por pessoas cujo objetivo único era o de construir computadores. $O$ fato é que eles foram descobertos, na década dos trinta, por físicos interessados em contar as partículas nucleares detectadas, uma vez que seus interesses principais giravam em torno da física nuclear.

Poder-se-ia inquirir se já estariamos utilizando a energia nuclear se a motivação básica tivesse sido simplesmente a procura de novas fontes de energia ou se a simples necessidade dessas novas fontes de energia nos teria conduzido à descoberta do núcleo atômico. Os fatos nos mostram que não ocorreu dessa maneira. A descoberta do núcleo foi devida à criatividade dos Curies, Rutherford, Fermi e outros.

Poder-se-ia perguntar se a indústria eletrônica existiria sem a prévia descoberta do eletron, feita por pessoas como Thomson e Lorentz. Novamente, não aconteceu assim.

Poder-se-ia conjecturar se os motores de indução poderiam ter sido criados por empresas cujos interesses eram os dos transportes motorizados e se assim teriam descoberto as leis da indução eletromagnética. O fato é que as leis da indução foram encontradas por Faraday na primeira metade do século XIX. Ou se, pressionados para produzir melhores métodos para os sistemas de comunicação, ter-se-iam descoberto as ondas eletromagnéticas. Estas não foram descobertas dessa maneira. Foram descobertas por Hertz, 
que enfatizava a beleza da física e que baseou os seus trabalhos nas considerações teóricas de Maxwell". "Creio que difícilmente pode-se encontrar um exemplo de inovação no século $\mathrm{XX}$, que não tenha um débito para com a ciência básica".

Estes exemplos são evidências do fato de que as pesquisas de fronteira da ciência, frequentemente, requerem técnicas que estão alem das possibilidades da tecnologia existente no momento. O cientista, em seu objetivo de conhecer e compreender a natureza, é forçado, e em geral o faz com sucesso, a utilizar toda a sua força de imaginação para ampliar tambem as próprias fronteiras da tecnologia. Esta é a razão "do porque" de inúmeras invenções tecnológicas terem a sua origem não no desejo de atender a um objetivo prático, mas sim na necessidade do desenvolvimento de ferramentas adequadas para a investigação dos profundos mistérios da natureza.

Nas ciências básicas, frequentemente, são investigados fenômenos ou objetos que não apresentam qualquer aparente posibilidade de aplicação. Por exemplo, o grande desenvolvimento da genética deve-se ao paciente estudo dos cromossomas de uma mosca inofensiva e despida de maior interesse: a drosófila. Os progressos científicos decorrentes dessas pesquisas foram enormes e a utilização desses conhecimentos, com resultados deveras extraordinários na agricultura, medicina e outros campos de aplicação, são amplamente conhecidos. Isto nos mostra que o comentário tão comum de que as instituições de amparo à pesquisa não devem investir em pesquisas onde o pesquisador pretenda "estudar a cor das asas das borboletas" deve ser encarado com cautela. Uma pesquisa, embora aparentemente exótica, como a mencionada, quando sugerida por sólidas razões científicas e desenvolvida por pesquisadores competentes, deve sempre ser amparada, pois pode conduzir a resultados da maior importância .

E extremamente dificil responder à questão de como deve reagir a comunidade científica face às prioridades sociais existentes no momento. A análise é delicada e dificil devido ao longo tempo( embora hoje este lapso de tempo esteja sistematicamente diminuindo) que frequentemente decorre entre a descoberta científica e as suas aplicações, e devido à grande incerteza que existe nas ligações entre qualquer área de investigação científica e seus possíveis impactos sociais. Exemplo claro é o da energia atômica. Em 1933 o próprio descobridor do núcleo atômico, Lord Rutherford, dizia:

"Anyone who expects a source of power from transmutation of these atoms is talking moonshine". 
Hoje, o aproveitamento da energia dos núcleos atômicos é uma realidade.

Negar a validade das pesquisas científicas básicas cujas aplicações a curto prazo, em termos do desenvolvimento econômico e social da nação, não possam ser vislumbradas seria cometer um erro de consequências desastrosas. Na nossa ignorância seria tão presunçoso negar a possibilidade da aplicação prática de uma descoberta científica como seria irresponsavel garanti-la.

Não se pode classificar as diferentes atividades científicas em duas categorias: uma que seja importante para as aplicações práticas e outra que não o seja. $O$ objetivo primordial da ciência não é o da sua aplicação mas sim o de estabelecer as leis que governam os processos da natureza.

Cabe ainda um comentário sobre o custo da pesquisa básica. $\mathrm{O}$ gasto total em ciências básicas, desde Arquimedes até os dias de hoje, é avaliado em cerca de US $\$ 30$ bilhões. Isto equivale a 12 dias de produção do parque industrial dos Estados Unidos, cujos produtos, em grande parte, são resultantes das conquistas científicas. Ainda nos Estados Unidos, gasta-se em astrologia (que certamente não é uma ciência) cerca de dez a vinte vezes mais do que o investido em astronomia!

Alguns economistas estudaram o papel da pesquisa no crescimento. Solow, analisando os dados estatísticos do período de 1909 a 1949 , concluiu que, nesse período, cerca de $90 \%$ do aumento da renda per capita foi devido ao progreso científico e tecnológico, enquanto que somente uma pequena parte desse crescimento foi devido ao aumento do capital investido por trabalhador!

A atitude 2 mencionada, que retrata a posição do público contra a ciência, traduz o seu desabafo contra as enormes dificuldades da vida moderna, que estão relacionadas com o ritmo da expansão tecnológica. Como o progresso tecnológico é em grande parte decorrente do avanço científico, não é surpreendente que a ciência seja responsabilizada pelas dificuldades que a sociedade moderna enfrenta.

Aqui devemos distinguir dois aspectos do problema: o aspecto sócio-político e o técnico-científico. A solução técnica, em um grande número de casos, não constitui problema sério. As consequências da aplicação ou não aplicação de algumas descobertas científicas podem, em geral, ser claramente apontadas pelo cientista. A grande dificuldade reside na aceitação de suas recomendações pelo público - um problema sócio-político. Existem casos em que os efeitos decorrentes 
da aplicação tecnológica não são conhecidos, como, por exemplo, os efeitos da urbanização na saude; os efeitos, a longo prazo, da produção do dióxido de carbono sobre o clima. Nestes problemas a ciência tem uma enorme tarefa. Mas, qual a importância das ciências básicas para a solução destes problemas? Não bastaria, para a solução destes problemas, a participação de técnicos orientados e especificamente treinados para estes tipos de problemas? Parece-me que não. A solução completa desses problemas com suas relações de causas e efeitos, leis e princípios, só pode ser obtida por pesquisadores treinados e habituados ao espírito da pesquisa básica. Sem esta profundidade é impossivel uma compreensão total e, sem esta, as consequências de uma solução técnica parcial e superficial podem ser extremamente danosas. A tecnologia pragmática acompanhada pela "ignorância das causas" não é mais admissivel hoje. Não tenho dúvidas de que se a sociedade atual criar condições culturais e sociais que não permitam o desenvolvimento e a utilização ampla das ciências, ela estará semeando a sua própria destruição. Os referidos "desastres" consequentes de uma sociedade tecnocrata só poderão ser contornados, controlados e contidos com o auxílio de uma ciência altamente desenvolvida, que possa e seja ouvida. Por exemplo, nos problemas ecológicos, onde é de suma importância o equilíbrio entre a preservação e o aproveitamento da natureza, os critérios científicos, e não os de ordem exclusivamente política ou econômica, é que devem prevalecer.

Finalmente, um comentário sobre a terceira atitude, que advoga a utilização do método científico (e aqui nos referimos especificamente às ciências naturais) em todas as áreas da atividade humana .

Estamos certos de que, para a solução dos inúmeros problemas que enfrentamos hoje, é necessária a aplicação dos métodos e conhecimentos das ciências naturais. Como já mencionamos, alguns desses problemas possuem uma grande componente sócio-política que envolve aspectos do comportamento do homem em situações complicadas e às vezes sofrendo transformações muito rápidas. Estes aspectos do comportamento não são susceptíveis de uma análise baseada exclusivamente nos métodos das ciências naturais. É tentadora a utilização destes métodos mas, provavelmente, as ciências sociais devem criar seus métodos próprios. A solução desses complexos problemas exige a participação coletiva de cientistas naturais, engenheiros, médicos, cientistas sociais, psicólogos etc. . As pessoas treinadas nas ciências naturais certamente desempenharão um papel importante e fundamental na solução desses problemas; serão necessários mas não suficientes. Existe sempre uma maneira científica de compreender qualquer fenômeno, mas existe tambem uma componente nas experiências humanas que escapa do quadro da ciência. Refiro-me às emoções, sentimentos e ao valor 
dos julgamentos. Estas são situações complementares. Estas situações complementares envolvem precisamente alguns aspectos importantes, mas que não se encaixam dentro do quadro lógico da ciência.

Este aspecto de complementaridade nos mostra que qualquer política de amparo às atividades de pesquisa deve ser ampla, aberta e de incentivo a todos os campos do conhecimento humano. $O$ progresso da Ciência e Tecnologia só adquire real significado se tiver por contrapartida um progresso equivalente no campo das Artes e das Humanidades.

O verdadeiro significado da Ciência se tornaria mais óbvio se cientistas e não cientistas tomassem maior consciência dos vários aspectos que discutimos. Muitas das críticas ao desenvolvimento científico e tecnológico perderiam força, o valor da Ciência no crescente conhecimento e compreensão dos fenômenos da natureza seria mais bem apreciado e o papel da Ciência na sociedade mais bem equacionado.

OSCAR SALA. Nascido em 26 de março de 1922 em Milão. Cidadão brasileiro por opção. Licenciado em Física em 1945 pela então Faculdade de Filosofia, Ciências e Letras da Universidade de São Paulo. Professor Titular de Física Nuclear desde 1962. Chefe do Departamento de Física Nuclear do Instituto de Física da Universidade de São Paulo. Presidente da Sociedade Brasileira para o Progresso da Ciência (S. B. P. C.) e diretor-científico da Fundação de Amparo à Pesquisa do Estado de São Paulo (FAPESP). Artigos publicados em revistas especializadas de Física. 